\title{
A BDI Approach to Infer Student's Emotions in an Intelligent Learning Environment
}

\author{
Patricia Augustin Jaques*1, Rosa Maria Vicari \\ PPGC- Instituto de Informática - Universidade Federal do Rio Grande do Sul \\ Bloco IV, Av. Bento Gonçalves, 9500 - Porto Alegre - RS - Brazil.
}

\begin{abstract}
In this article we describe the use of mental states approach, more specifically the BDI model, to implement the process of affective diagnosis in an educational environment. We use the psychological OCC model, which is based on the cognitive theory of emotions and is possible to be implemented computationally, in order to infer the learner's emotions from his actions in the system interface. In our work we profit from the reasoning capacity of the BDI approach in order to infer the student's appraisal (a cognitive evaluation of a person that elicits an emotion), which allows us to deduce student's emotions. The system reasons about an emotion-generating situation and tries to infer the user's emotion by using the OCC model. Besides, the BDI approach is very adequate since the emotions have a dynamic nature.
\end{abstract}

Key-words: architectures for educational technology system, distance education and telelearning, human-computer interface, intelligent tutoring systems, interactive learning environments, media in education.

\section{Introduction}

Due to the traditional dichotomy in the Western society between reason and emotion, which was inherited from Descartes' dualist vision of the mind and body, in the last century little attention has been paid to the role of the affectivity in cognition and learning. As it occurred in a real class, educational computing environments considered only the cognitive capacities of the student and his knowledge in order to make the system more customized to him.

However, recent works of psychologists and neurologists have been pointing out the important role of the motivation and of the affectivity in cognitive activities, such as learning (Damasio, 1994; Izard, 1984). Psychologists and pedagogues point out the way that the emotions affect learning (Goleman, 1995; Piaget, 1989; Vygotsky, 1994). Due to this important role of the affectivity in learning, researchers of the Computer in Education field have studied techniques of Artificial Intelligence in order to turn the educational systems more customized also for the affective states of the student.

The field of Artificial Intelligence that researches about emotion in computers is called "Affective Computing". Picard (1997) defines Affective Computing as "computing that relates to, arises from or deliberately influences emotions". Following Picard (1997), an affective (computational) system must have a few of the following capacities: (1) recognize, (2) express, or (3) possess emotions. We observe that the Affective Computing field is divided into two major branches of research interest. The first one studies mechanisms to recognize human emotions or to express

\footnotetext{
* Corresponding author. fax: +55 513316 7308, e-mail address: pjaques@inf.ufrgs.br

${ }^{1}$ Patricia had a Brazilian CNPq Scholarship.
} 
emotions by machine in human-computer interaction. The second branch investigates the simulation of emotion in machines (emotion synthesis) in order to discover more about human emotions and to construct more realistic robots. In Figure 1, we can see a schema that illustrates the two branches of the Affective Computing field.

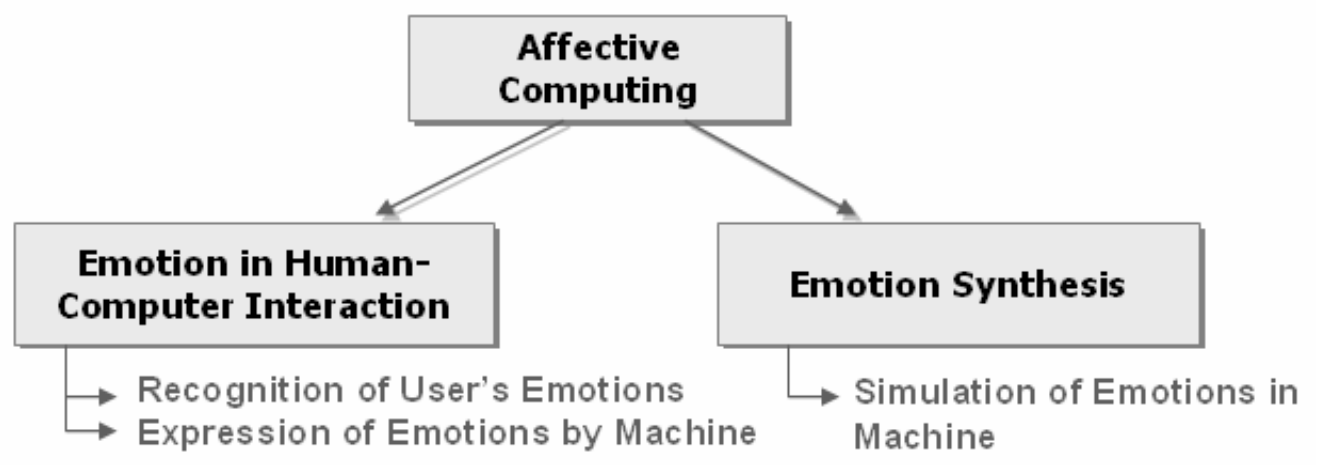

Figure 1: The Research Branches of the Affective Computing Field

The researchers of Computer in Education are more concerned with the former branch of investigation of the Affective Computing research, since they are especially interested in recognizing the student's emotions and showing emotions in the interaction between the artificial tutor and the student.

In order to adapt the system to the student's affectivity, the system should recognize the student's emotions. For example, when the student is disappointed with his performance, he will probably abandon the task. The system needs to know when the student is disappointed in order to encourage him to carry on studying and accomplish the task. The affective history of the student, all the affective states that he felt while using the educational system, should be maintained in an affective student model in order for the educational system to respond appropriately for the student's emotions. This affective model must be dynamic enough to consider the changes in emotional states.

This article presents a mental states approach, more specifically the Belief-Desire-Intention (BDI) model (Georgeff, 1999), to recognise and model student's emotions in an educational environment. We infer satisfaction/disappointment, joy/distress, gratitude/anger and pride/shame emotions according to OCC psychological model (Ortony, Clore and Collins, 1988) from student's observable behaviour. More specifically, we profit from the reasoning capacity of the BDI approach to infer student's emotions from his actions in the system interface using a cognitive-based psychological model of emotion: OCC. The agent reasons about the student's actions and events in the educational system and to which emotions these events lead according to the student's goals.

This affective information about the student is used by an animated pedagogical agent, called Mediating Agent, that is responsible for motivating the student and promoting positive emotions in him, which fosters learning. This careful support of the agent, its affective tactics, is expressed through emotional attitudes and by encouragement messages of the lifelike character. In this paper we focus only on the affective diagnosis using a BDI model, but more details about this affective agent can be found in (Jaques \& Viccari, 2004) and (Jaques et al., 2004). This agent is part of the multi-agent architecture of an educational collaborative system. The paper (Andrade et al., 2001) describes this collaborative educational environment.

This article is organised in the following way: first, in Section 2, we present a definition of emotion and motivation. In Section 3, we explain all the steps necessary to model the inference of emotions in an intelligent learning environment using a cognitive based psychological model of emotions. In Section 4, we describe the X-BDI model, the tool used in this work for the implementation of the cognitive module of the agent that infers the student's emotions. In the Section 
5, we show a scenario the inference of emotions in BDI. Finally, in Section 6 we describe the conclusions and some ideas of future work.

\section{What are Emotions, Moods and Motivation?}

In order to better understand the work in affectivity and emotions in an intelligent learning system we first need to understand what emotions are. Although this term is popularly used for many phenomena of affective order, these phenomena should be denominated by the generic term "affective state" that can be seen as more wide-ranging, which also includes other states besides emotions, such as moods (Scherer, 2000; Frijda, 1994).

According to Scherer (2000), emotion is the relatively brief episode on synchronized responses for most or all organic systems for the evaluation of an external or internal event as being of major significance. Some examples of emotions are anger, sadness, joy, fear, shame, pride, and desperation. Ortony, Clore and Collins (1988) propose a similar but more precise definition for emotions. According to them, emotions are valenced reactions to events, agents, or objects, with their particular nature being determined by the way in which the eliciting situation is constructed. According to this definition, surprise is not an emotion since it does not have a valence. Frijda (1994) considers that the emotion is an intentional mental state, because it is "directed toward" an object, its intentional object. For instance: I am angry with John, but I admire Nicholas.

The works on affectivity and education have also considered the motivation of the student. Student motivation deals with the student's desire to participate in the learning process (Ames, 1990). In earlier studies, motivation was seen as a personality trait, as something people had in higher or lower degrees, a depending part on their genetic nature and on their childhood experiences (Meece \& McColskey, 2001). However, nowadays researchers believe that motivation is sensitive to contexts and it can be fostered in the classroom. This way, a lot of works have developed in the sense of fostering student's motivation to learn in educational computing systems (Del Soldato \& De Boulay, 1995; Bercht \& Viccari, 2000; De Vicent \& Pain, 2002).

In this article, we are going to handle specifically student's emotions.

\section{Recognising and Modelling User's Emotions}

In order for an affective computational system to interact effectively with the user, it must recognise the user's emotions to respond to him appropriately. At present, we observe four main modes of user's emotion recognition: (1) voice (prosody) (Kopecek, 2000; Tcherkassof, 1999); (2) observable behavior, i. e. user's actions in the system's interface (for example, chosen options and typing speed) (Bercht \& Viccari, 2000; de Vicente \& Pain, 2002; Jaques et al., 2004a; 2004b); (3) facial expressions (Ekman, 1999; Wehrle \& Kaiser, 2000); and (4) physiological signs (blood volume pulse, electromyogram - muscle tension, skin conductivity, breathing) (Picard et al., 2001).

Generally, these emotion recognition mechanisms, such as emotion recognition by the user's facial expressions, physiological signs or voice, are composed of a hardware equipment which detects the physiological signs, and a software component that is responsible for decoding the information sent by the equipment. For example, Wehrle and Kaiser (2000) videotaped the user's facial expressions while playing a game and used the software FEAT to automatically analyze the recorded facial behavior.

We can recognize the student's emotions just by analyzing his facial expressions or voice, but, usually, the physiological sensors are not used as the unique mechanism to infer the student's emotions. Since they only yield some evidence on the arousal, valence and other information about the 
emotions, they are used as auxiliary mechanisms to infer the emotions more accurately, or together. An example of a measure taken by a physiological sensor is the heartbeat (measured from a heart rate monitor), which just indicates the presence of emotion with negative valence (Picard, 1997).

The emotion can also be inferred by the student's observable behavior, i. e, student's actions in the interface of the learning environment. Some examples of observable behavior are: time to accomplish an exercise, success or failure in tasks, request or refuse help, etc. In such cases, generally the system predicts the user's emotions based on a cognitive psychological model of emotions, for example the OCC model (Ortony, Clore \& Collins, 1988). The idea is to use the information provided by the psychological model in order to build an interpretation of a situation from the user's point of view and to reason about which emotion this interpretation leads to.

In our work we recognise the joy and distress, satisfaction and disappointment, gratitude and anger, as well as pride and shame emotions ${ }^{2}$ by the student's observable behaviour. The inference of these emotions is based on the OCC model (Ortony, Clore \& Collins, 1988): a psychological model based on the cognitive approach of emotions that explains the origins of emotions by describing the cognitive processes that elicit them. This cognitive process that elicits an emotion is called appraisal by the cognitive theoreticians of emotions. The central idea of the appraisal theory is that the "emotions are elicited and differentiated on the basis of a person's subjective evaluation of the personal significance of a situation, event or object on a number of dimensions or criteria" (Scherer, 1999). The appraisal consists in this evaluation of value of personal meaning for a situation. Let us see an example: Nicolas and Rafael are watching a football game that their favourite teams are playing. Rafael's team win. Nicola's appraisal is that an undesirable event happened: his team lost. He is sad. According Rafael appraisal the same situation is a desirable event and he feels happy.

According to OCC model, joy and distress emotions arise when the student is pleased because a desirable event happened (joy) or unpleased because an undesirable one happened (distress). The desirability of the event is evaluated according to student's goals. For example, for a determined student which has the goal of pleasing the teacher and his parents, obtaining a good grade is a desirable event and, in this way, will elicit joy emotion. Figure 2 illustrates the appraisal for joy and distress emotions according to the OCC model. The square named appraisal in the figure illustrates the appraisal for these emotions.

\footnotetext{
${ }^{2}$ We chose these 8 emotions because they influence in the learning process of the student. For example, a frustrated student abandons the task easily than a satisfied student, so it is important for an educational system to know when the student is disappointed (frustrated) in order to encourage him to persist in the task. But, as the educational system where the Mediating Agent is inserted is a collaborative one, we intend in a future work to consider emotions that are elicited from the interaction among students.
} 


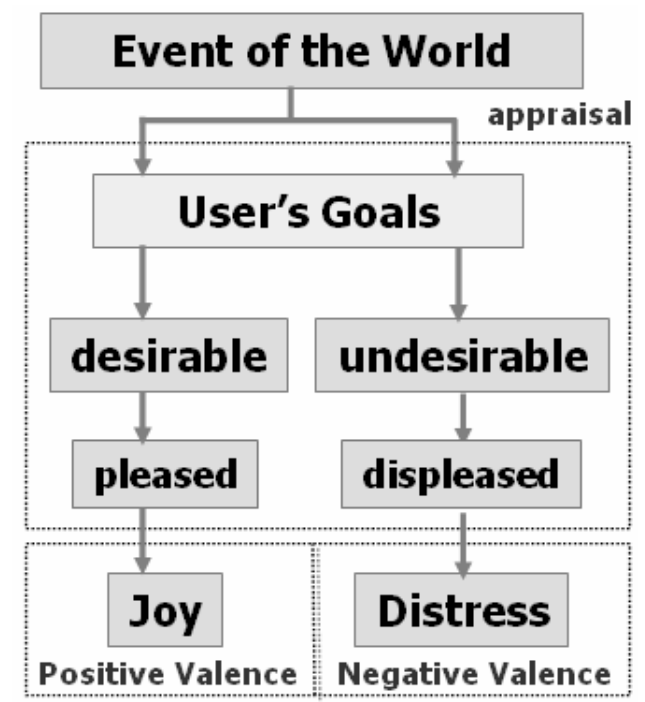

Figure 2: Scheme Representing Appraisal for Joy and Distress Emotions according to OCC Model

The important point about joy and distress emotions is that they result from focusing only on the desirability or undesirability of the event. A person can also focus on other aspects of the events as well, for example that it was anticipated, or that some person was responsible for bringing it about. When this happens, different forms of emotions arise. This is the case of satisfaction and disappointment emotions. When the students focus on expected and suspected events and in the confirmation, or not, that these events will happen or happened; satisfaction and disappointment emotions can be elicited. The satisfaction emotion arises when one is pleased about the confirmation of the prospect of a desirable event and disappointment when one is displeased about the disconfirmation of the prospect of a desirable event. For example, if the student expects to have provided a correct response to an exercise (desirable event) and it did not happen (disconfirmation of the prospect of the desirable event), he experiences disappointment emotion. Figure 3 presents a scheme that illustrates the appraisal for satisfaction and disappointment emotions. Know when the student feels satisfaction and disappointment emotions help the agent to detect the student's engagement, since, generally, when the student is satisfied, he is more engaged in the course than when he is disappointed. 


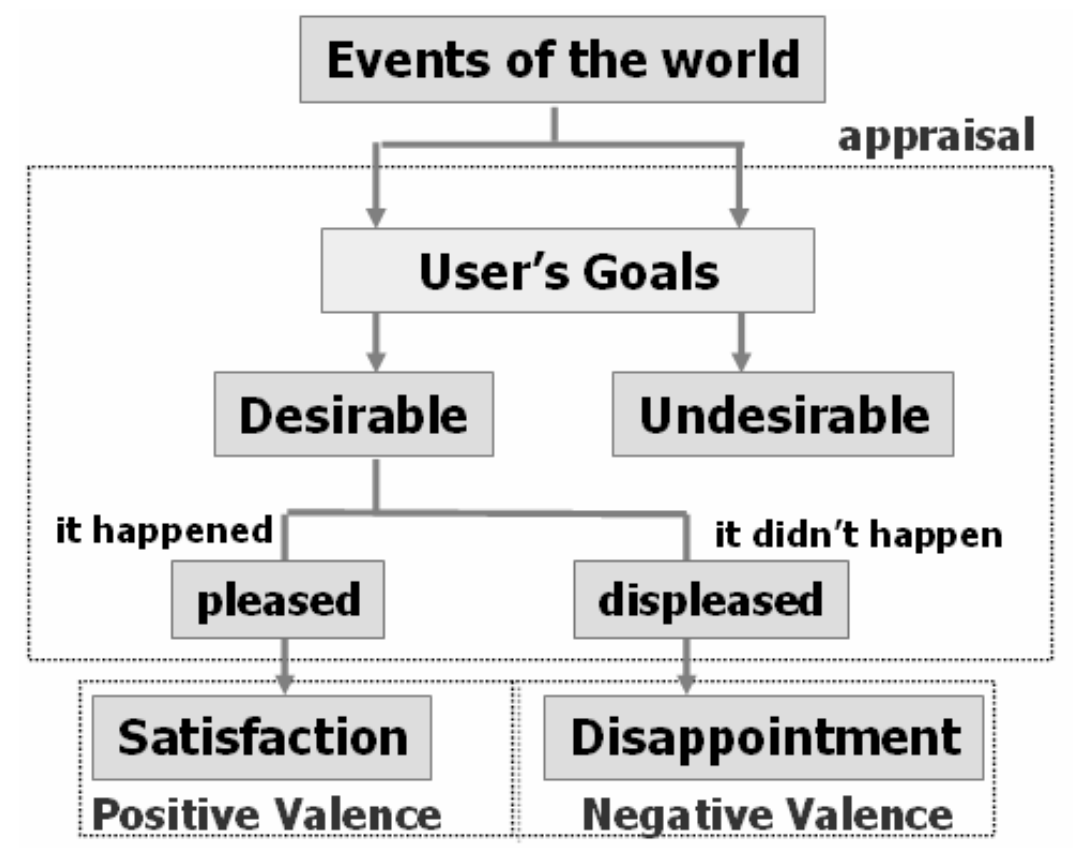

Figure 3: Scheme Representing Appraisal for Satisfaction and Disappointment Emotions according to OCC Model

The student can also focus on the agent that causes the undesirable/desirable event for him and, in this case, he will experience gratitude and anger emotions. The recognition of these two emotions helps the agent to estimate how helpful it is being for the student. The OCC model defines the gratitude emotion as approving of someone else's praiseworthy action and being pleased about the related desirable event. Anger arises when one disapproves someone else's blameworthy action and is displeased about the related desirable event. In our educational system, the emotion of anger arises when the student evaluates that an action of the Mediating Agent interferes in his goals, and gratitude arises when an action of the Mediating Agent promotes his goals. Figure 4 shows a scheme representing the appraisal for gratitude and anger emotions according to the OCC model.

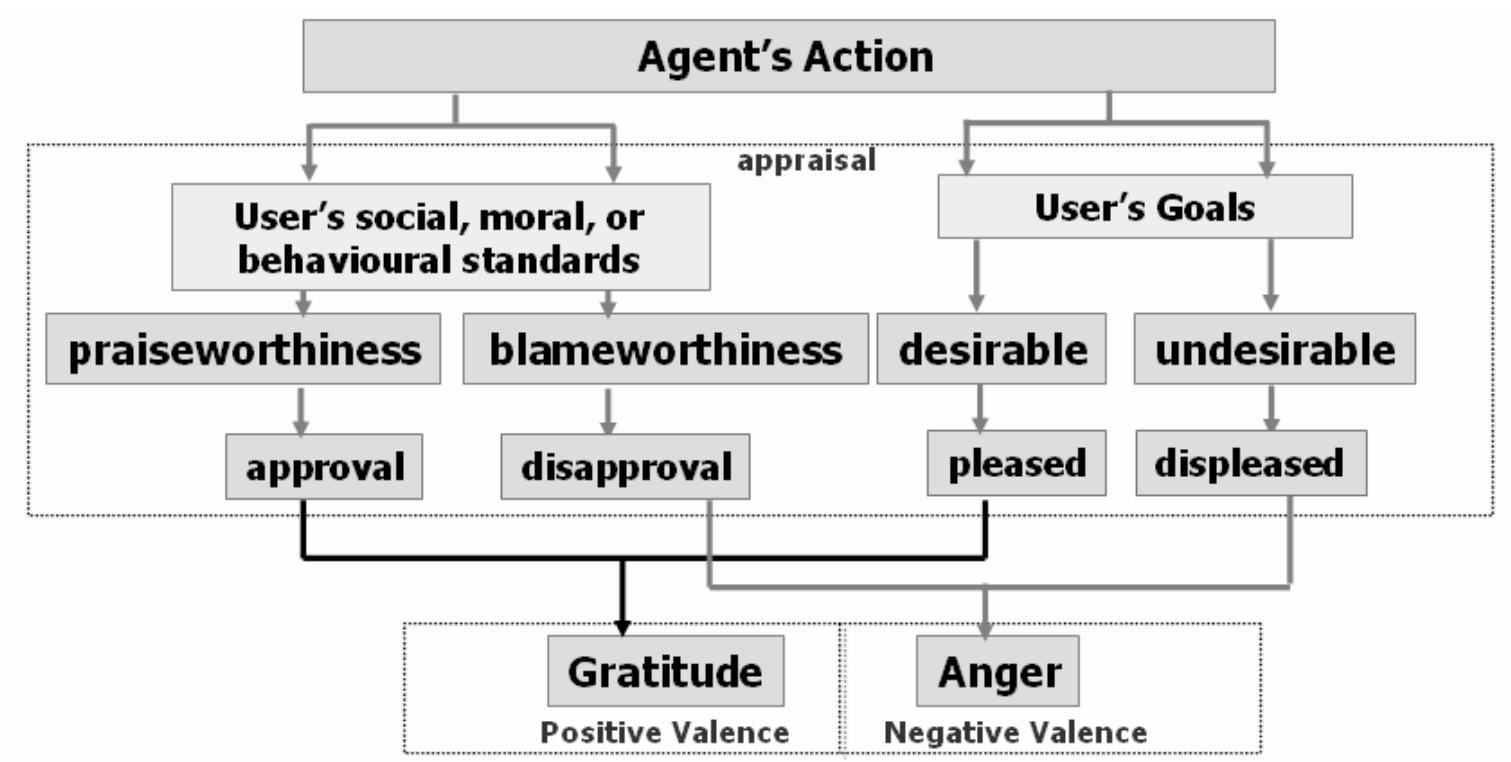


Figure 4: Scheme Representing Appraisal for Gratitude and Anger Emotions according to OCC Model

Besides, the student can feel shame or pride when the agent that caused the undesirable action is himself. Pride arises when a person approves his praiseworthy action and shame when this person disapproves his own blameworthy action. For example, a performance oriented student can feel shame of asking help for the agent because it means lack of ability in his point of view. Figure 5 represents the appraisal for the pride and shame emotions.

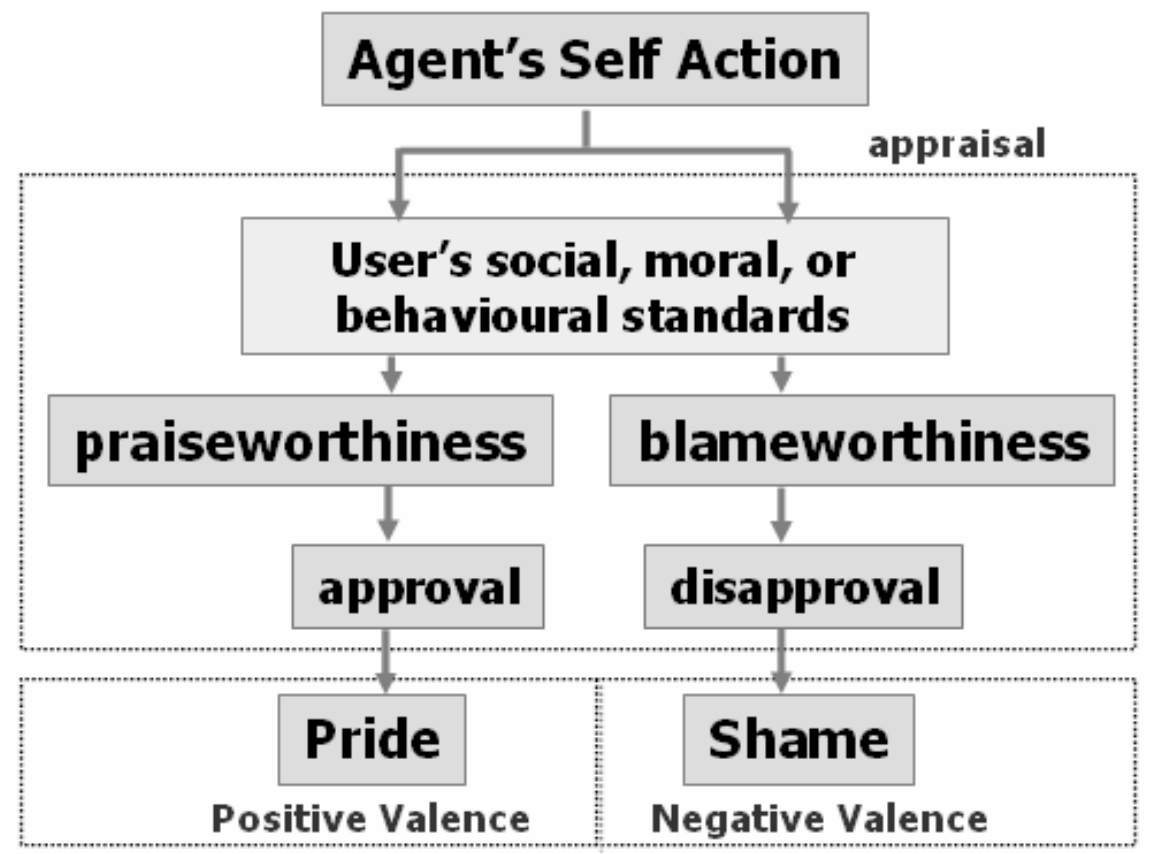

Figure 5: Scheme Representing Appraisal for Pride and Shame Emotions

When the student has emotions as pride/shame and gratitude/anger, the emotions are towards the Mediating Agent, which is an inanimate object. Although it seems unreasonable that the student has emotions towards a computer program, it is what happens in real-life, as show the works of Reeves and Nass (1996). They assert that people interact with machines as if they were social actors and, in this way, feel emotions that they feel when interact with other humans.

According to the OCC model, emotions are always valenced reactions. Joy and distress emotions are opposite valenced reactions for the evaluation of events, satisfaction and disappointment for the prospect of events, gratitude and anger for the actions of another agent, as well as pride and shame for the actions of the agent itself.

As the process of recognition is similar for all emotions, in this article, we are going just to focus on the inference of joy/distress and satisfaction/disappointment emotions. We chose to show the inference of these four emotions, since the emotion inducing situations are the same for them. So, what we do, for the case of recognising joy/distress and satisfaction/disappointment emotions, is verify when an event of the educational environment is desirable or undesirable for the student (according to his goals) and when the student is pleased because a desirable event happened or displeased because an undesirable one happened (in order to detect joy and distress), or yet pleased because a expected desirable event happened or displeased because it did not happen (in order to detect satisfaction and disappointment). This way, we need to define (1) the events that can happen in the educational system, (2) the user's goals (in order to know if the event is desirable or not), and (3) the desirability of the events (according to student's goals) in order to infer the student's emotions. In the next sections we describe these steps. 


\subsection{Determining the Events in the Educational Environment}

Events are the way people perceive things that happen. "They are people's construals about things that happen, considered independently of any beliefs they may have about actual or possible causes" (Ortony, Clore \& Collins, 1988, p. 18). In our educational environment the events can be caused by either a student's action or a Mediating Agent's action (the artificial tutor). In a computational environment for learning a great number of events can arise. For our study and prototype's implementation, due to complexity of the inference of emotions using a cognitive-based affective user modelling (infer the emotions using a cognitive psychological model of emotions), we chose some simpler events, but we believe that these events are sufficient to validate the ideas behind this work.

Table 1 shows some events that can happen in our educational environment and which are analysed in this work.

Table 1: Events in the Educational Environment that Elicit Joy/Distress and Satisfaction/Disappointment Emotions

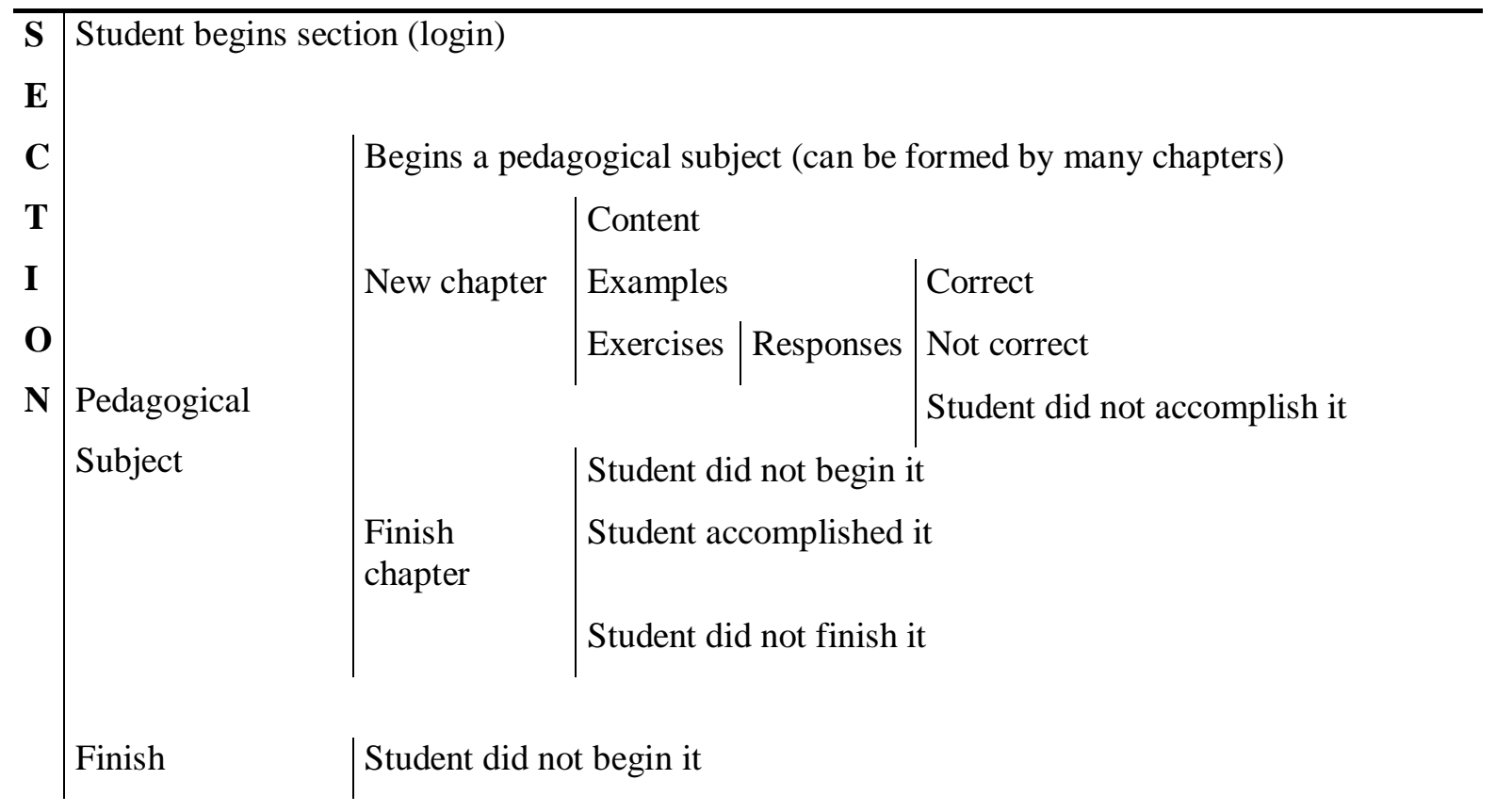


\begin{tabular}{|l|l} 
Pedagogical & Student accomplished it \\
Subject & Student did not finish it
\end{tabular}

Finish Section (logout)

The pedagogical scheme is formed by different pedagogical items, for example, a chapter or a section. Each chapter (or another item) is composed of a pedagogical content, examples and exercises. At each chapter, the student asks the agent to go to the next chapter or to return to the previous one. He can yet read an explanation about the topic, see examples and resolve exercises. For each exercise, he can provide a correct or incorrect response, or yet to choose not accomplish it. If the student made all activities suggested in the chapter, he accomplished it. He can still to choose not begin a chapter or not to finish it. He can choose the same options for the pedagogical subject.

Table 2 shows the events in the educational environment which were caused by the Mediating Agent. When these events (that are the Mediating Agent's actions) are evaluated by the student, they can elicit emotions of gratitude or anger in relation to the agent that causes them, in this case, the Mediating Agent.

Table 2: Events in the Educational Environment that Elicit Gratitude or Anger Emotions

\begin{tabular}{|c|c|c|c|c|}
\hline A & & & & \\
\hline G & & Agent offers help & Student denies a & gent's help \\
\hline $\mathbf{E}$ & & & Student accepts & Specific Help \\
\hline $\mathbf{N}$ & Help & & & Generic Help \\
\hline$T^{\prime}$ & & & & \\
\hline $\mathbf{S}$ & & $\begin{array}{l}\text { Student asks for } \\
\text { help }\end{array}$ & Specific Help & \\
\hline A & & & Generic Help & \\
\hline C & & & & \\
\hline $\mathbf{T}$ & Message & Agent present a m & age of encourage & ment and motivation to the student \\
\hline I & & & & \\
\hline $\mathbf{O}$ & Behaviour & $\begin{array}{l}\text { Agent presents a s } \\
\text { and create a positi } \\
\text { followed by a mes }\end{array}$ & $\begin{array}{l}\text { dence of animatio } \\
\text { mood in the stude } \\
\text { ge. }\end{array}$ & $\begin{array}{l}\text { ns that aims to encourage, motivate } \\
\text { ent. This behaviour is usually }\end{array}$ \\
\hline $\mathbf{S}$ & & & & \\
\hline
\end{tabular}


The student can ask for help or the Diagnostic Agent ${ }^{3}$ can decide to offer some help to the student. This help can be specific or generic. A generic help provides examples, formulas and explanations for an exercise or pedagogical subject. The specific help shows how to accomplish an exercise. The student can deny the help offered by the agent, but the agent always accept the help asked by the student.

As the agent is a lifelike agent with artificial voice, it can present animations and messages of motivation and encouragement to the student.

The system is available on the Internet. This way, the student must logon each time he desires to use the system.

\subsection{Determining the Student's Goals}

Secondly, we need to define the student's goals in order to determine if the events of the world are desirable according to these goals and when the student is pleased/displeased with the occurrence or not of these events. Ortony and colleagues (1988) define a goal as the kinds of things that can be pursued and the kinds of things for which one believes that one can develop a plan for them to be realised.

And in an educational situation, what goals does the student have?

According to Ames (1990), students can have mastery or performance motivational orientation, which are the reasons for students engaging in learning and choosing to engage in academic tasks. We found in the motivational orientation theory some cues that help us to determine the student's goals.

When students have performance motivational orientation they believe that performance is important and want to show that they have abilities (Ames, 1990). They feel successful when they please the teacher or do better than other students, rather then when they learn something new. When these students experience difficulty, they are not likely to increase their effort because this shows lack of ability according to their point of view. As they are primarily motivated by extrinsic factors (grades, parent approval, etc), they are also called extrinsically motivated.

Students that have mastery or learning motivational orientation are oriented toward developing new skills and abilities, trying to understand their work, improving their level of competence and learning new things (Ames, 1990). "They resolve an activity for its own sake, for the enjoyment it provides, for the learning it allows, or for the feeling of accomplishment it evokes" (Lepper, 1988). These individuals make efforts to learn something new or when they confront challenging tasks. When they experience difficulty, they increase their efforts because they believe that the attempt is necessary for success or improvement (Meece \& Mccolskey, 2001). They are also called intrinsically motivated.

In Figure 6 we can see an imaginary structure of goals for students that have performance motivational orientation and in Figure 7 for students that have mastery motivational orientation. These schemes were made based on the macro-structure proposed by (Ortony; Clore \& Collins, 1988) and about the characteristics of extrinsic and intrinsic motivated students described in some pedagogical studies (Järvela, 1998; Ames, 1990; Meece \& Mccolskey, 2001).

\footnotetext{
${ }^{3}$ The Diagnostic Agent is another agent that composes the multi-agent architecture of the educational environment where the Mediating Agent is inserted. It has the goal of accomplishing the cognitive modelling (intellectual student's model) and also to choose the scaffold tactics.
} 
This scheme aims at offering a simplified view of the student's goals. As Ortony and colleagues state, indeed, it seems that this structure is more complex than a tree, as they propose; even though its overall shape is probably treelike. The high-level nodes represent fairly abstract goals that might be characterised as aspirations or general concerns, while the nodes at the lowest level are the more concrete immediate goals. The nodes have connections with the other goal nodes. Incoming connections represent those goals whose achievement can be affected by the achievement of lowerlevel goals from which the links come. For example, in order to achieve the "please the teacher and parents" goal (Figure 6), the student must obtain "good grade". This same connection is an outgoing one for the "good grade" goal.

When a goal has multiple outgoing connections, it means that the achievement of that goal can directly affect other goals. So, for example, attaining the "good grade" might affect not only a "please the teacher and parents" goal, but also a "do better than other colleagues" goal, and "show that has a high level of competence" goal.

While outgoing links are usually conjunctive, i. e. a goal can have many consequences, incoming links can be conjunctive or disjunctive. Disjunctive incoming links represent alternative ways for achieving the goal. The conjunctive links represent those links that must be achieved together for the accomplishment of the goal in question. To represent conjunctive and disjunctive goals, we use the nomenclature proposed by Ortony and colleagues. According to them, the links can be classified as sufficiency, or necessary, or facilitative, or inhibitory links. Sufficiency (marked with an $\mathbf{S}$ in the Figure 6) links are those that can be considered in some degree sufficient to achieve the goal. No particular one of the sufficiency links is necessary, but it is necessary that one of them succeed. In the conjunctive case, the links are all to some degree necessary (marked with an $\mathbf{N}$ ), none of them alone being sufficient. Besides, a link can also be facilitative (marked with an $\mathbf{F}$ ), which means that it is neither necessary, nor sufficient, but when achieved, it increases the probability that a higher level goal will be achieved even though it does not guarantee it. Furthermore, a link can also be inhibitory (marked with an I), which means that the sub-goal reduces the probability of attaining the high-level goal.

As Figure 6 shows, a performance oriented student have as high-level goals "please the teacher and parents", "do better than other colleagues", and "show that he has a high level of competence". In order to "please the teacher and his parents" it is sufficient that the student has good grades. To achieve the goal "do better than his colleagues" it is necessary that he obtains good grades, but he should also obtain better grades than his colleagues. But in this work we do not consider the affective aspects of the collaborative learning. In order for the student to "show that he has a high level of competence" it is necessary that he obtains "good grades", makes "low effort" and "does not ask for help" (since he believes that make high effort and ask for help mean lack of ability). "Provide a correct response for the exercises" is sufficient to "have success in the activities", which is sufficient to have "good grade". In order to "have success in the activities", the student must "finish the proposed activities". "Receives appropriate help" from the Mediating Agent can facilitate his goal of "having success in the activities". 


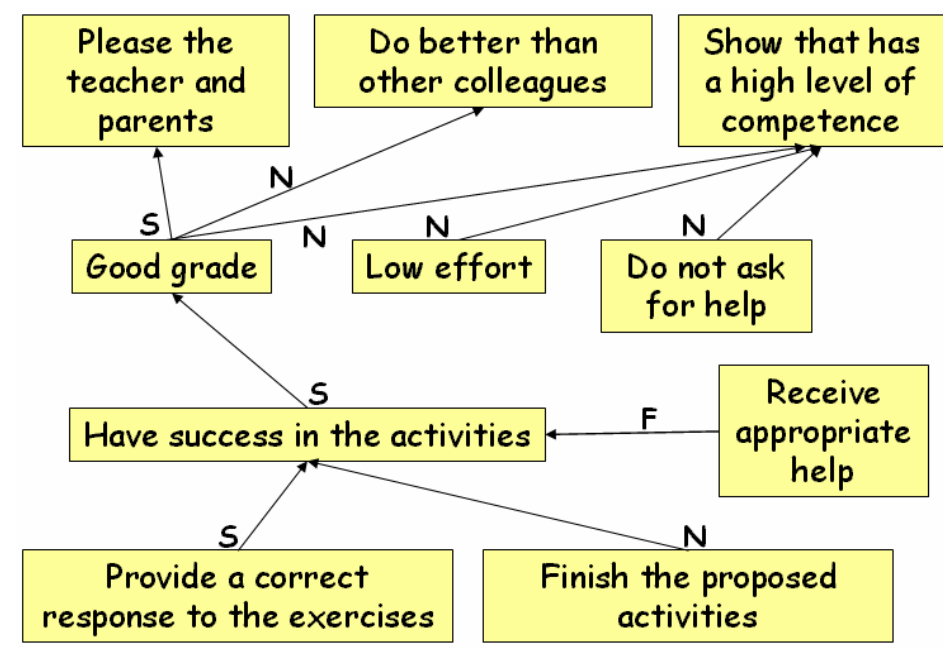

Figure 6: Virtual Goal Structure of a Performance Oriented Student

Figure 7 shows the virtual goal structure for intrinsically motivated students. The intrinsic student has the goals of "developing new skills", "improving his level of competence", and "learning new things". The goals of making "high effort" and "receive appropriate help" of the Mediating Agent are necessary to achieve the other goals. To "ask for help" when having difficulties and to "finish the proposed activities" can facilitate the achievement of the high-level goals. The mastery student believes that to "have success in the activities" can facilitate his high-level goals, since it shows that the student learned the taught subject. To the student "have success in the activities" is sufficient to "provide a correct response for the exercises". 


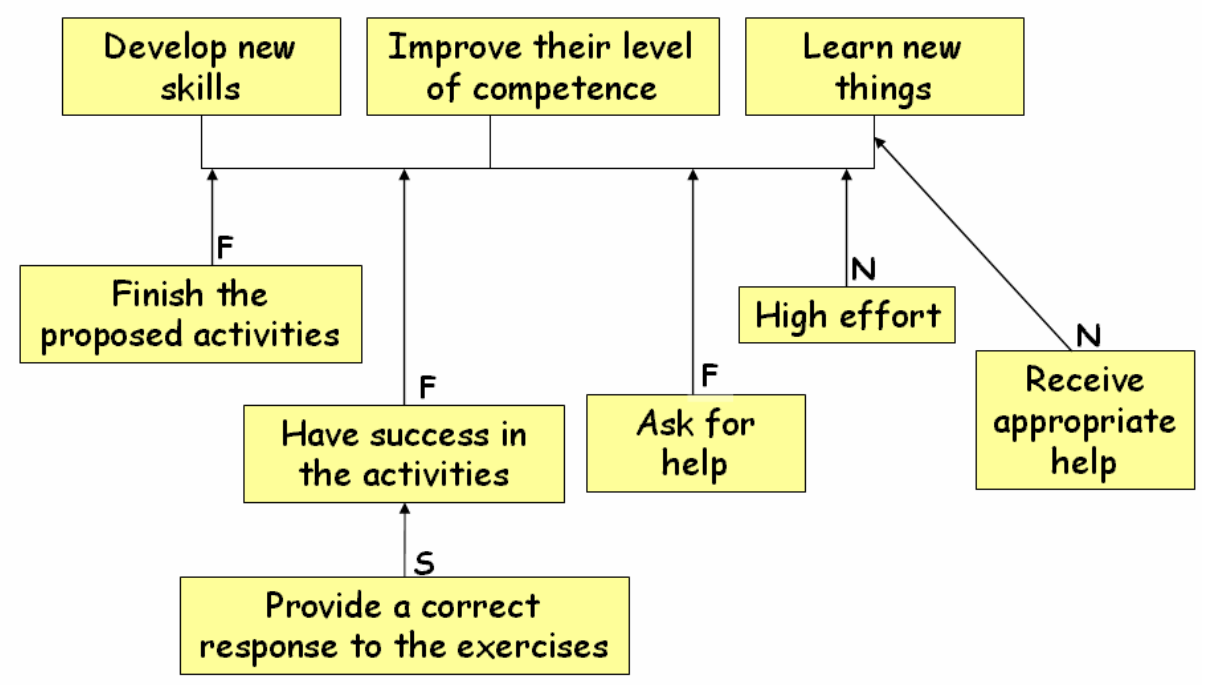

Figure 7: Virtual Goal Structure of a Mastery Oriented Student

In order to identify the student's goal orientation we use the Motivated Strategies for Learning Questionnaire (MSLQ) (Pintrich et al., 1991). The MSLQ is a self-report instrument which allows to determine students' motivational orientation and learning strategies. It is based on a cognitive view of motivation and learning. MSLQ was developed by a group of researchers from the National Center for Research to Improve Postsecondary Teaching and Learning and the School of Education at University of Michigan.

To determine students' motivational orientation, the questionnaire has 8 items (questions). For each question, the student must provide a response that can be a number between 1 and 7 which means how true is the item for the student ( $1=$ "Not at all true for me" and $5=$ "Very true for me."). For example, the following item is part of the Mastery goal orientation section of the questionnaire: "In a class like this, I prefer course material that really challenges me so that I can learn new things". As example of an item of the Performance goal orientation section, we can cite "Getting a good grade in the class is the most satisfying thing for me right now". In the current version of the system, this questionnaire is applied in the first time that the student accesses the educational system.

Sometimes, it could not possible for the system to determine the student's goals in a determined situation, for example, if an intrinsic motivated student is interested in a determined pedagogical content. In this case, the system can make some questions to the student, as we explain in Section 3.5, but it is necessary to limit the number of questions in order for the interaction with the system does not be tedious for the student.

\subsection{The Event's Desirability}

Thirdly, once we know the student's goals and the events that can arise in our educational system, we can determine the desirability of the events and also when the student is pleased/displeased with an event. This process is necessary to infer the student's appraisal, i. e., the cognitive evaluation that elicits emotions. This way, we classified the events according to their desirability based on what we know about student who have mastery or performance goals (described in the previous section). With this information, we can determine student's emotion in our system. The student can be pleased with desirable events or displeased with undesirable ones. When he is pleased, he feels joy. When he is displeased, he feels distress. But, as mastery and performance students have different goals, the same situation (event) can lead to opposite emotions. For example, let us consider the event "to 
provide an incorrect response to an exercise". For a performance oriented student, this event is always undesirable (and, so, the student is displeased) because he has the goal of pleasing his parents. For a mastery student, the desirability of the event will depend on his curiosity about the subject.

Furthermore, the emotion that is elicited depends mainly on the person's interpretation of a situation and on which aspects of a situation this person focuses. Ortony, Clore and Collins (1988) describe an example: let's suppose a person learns that his neighbour is a merciless child-beater. If such a person focuses only on the neighbour's role as the agent of child-beating, he will probably have reproach emotion. The person can focus on the aspects of the child-beating event and if it focuses only on its undesirability he will probably feel distress. He could also focus on his neighbour's children and experience pity. Finally, the person can focus on his neighbour and feels hatred. In this way, some student's actions are evaluated according two points of view: (1) as student's actions and, so, can elicit shame or pride emotions; and (2) as events and, in this way, can generate joy, distress, satisfaction, and disappointment emotions. It is the case of the student's action "to provide an incorrect response to an exercise". For a performance oriented student, this situation can be seen as a blameworthiness action of himself (this interpretation elicits shame emotion), or an undesirable event that happened (this interpretation elicit distress emotion), or yet am expected desirable event (provide a correct response) that was disconfirmed (this interpretation elicits disappointment emotions). So, the emotion that is elicited is the effect of focusing on different aspects of an emotion-inducing situation.

In reality, according to the $\mathrm{OCC}$, it is more probable that "a person will experience a mixture of emotions resulting from considering the situation from different perspectives at different moments so that some of the resulting emotions may co-occur and some will occur in sequences" (Ortony, Clore \& Collins, 1988, p. 21). This is the case of satisfaction/disappointment and joy/distress emotions. For example, because satisfaction results from the confirmation of a desirable event, the eliciting conditions for joy emotions will be satisfied by virtue of that desirable event. The OCC model asserts that, for the cases when two emotions co-occur that are compatible in this way (i.e., the elicitation of one entails the elicitation of the other), the most intense emotion presents itself to conscious awareness more insistently than the least intense one. In general, satisfaction is more likely to be available in consciousness when the desirability of the event in question is not very high. We consider in our work that all events that are expected elicit a mixture of satisfaction and joy emotions (when they have positive valence), or disappointment and distress (when they have negative valence). If the event is not expected, it elicits only joy or distress emotions, since satisfaction and disappointment are valenced reactions for the prospect of an event. As pointed out by the OCC authors, although people experience a mixture if emotions, identify each emotion disconnectedly seems to be the first step to identify this mixture of emotions that happens in real life.

\subsection{Intensity of the Emotions}

An emotion has always a determined intensity. According to the OCC model, the intensity of the emotions depends on some variables. The intensity of the joy/distress emotions depends mainly on the degree to which the event is desirable or not. The intensity of emotions satisfaction/disappointment also depends on the desirability of the event, on the effort made for the accomplishment of the event, and on the realization of the event (the degree to which the confirmed or disconfirmed event is realized). The intensity of gratitude and anger emotions depends also on the desirability of the event. Besides, the OCC theory considers that other global factors (that affect all OCC model's emotions) must also be considered: the event's unexpectedness (unexpected positive things are evaluated more positively than expected ones).

The degree of desirability of an event can be measured through the information that we have about performance and mastery oriented students. For example, we know that mastery oriented students desire more strongly to obtain a high grade. In order to measure the student's effort, we use Soldato's model of effort (del Soldato \& de Boulay, 1995). In Soldato's model the student effort is 
inferred from his persistence in the resolution of exercises and asking for help assistance, and can have one of the following degrees: minimal, little, medium, big and maximal. The realization variable can also be considered. For example, when an extrinsically motivated student wants to obtain an excellent grade to please the teacher, if he just obtains a good grade, he achieves his goal partially. For the performance oriented student who usually receives average grade, to receive the maximal grade is an event with high unexpectedness and, so elicits the satisfaction emotion with a higher intensity.

Due to the complexity of determining emotions' intensity by some cues from the student's observable behaviour, the current version of the prototype identifies just two degree of intensity: medium and high. But, in order to determine the emotions elicited and their intensity with more accuracy, the system foresees the insertion of other physiological sensors, such as skin conductivity and heartbeat sensors.

\subsection{The Student's Emotions}

Table 3 shows the emotions that are elicited, for each event, for students who have mastery goal orientation and Table 4 presents the emotions that are elicited when the students have performance goal orientation. As previously explained, in this paper we are just to focus on the inference of joy/distress and satisfaction/disappointment emotions. In the column "Events" we present the events (or student and agent's actions) that can happen. Once we know the student's goals and the events that can arise in our educational system, we can determine the event's desirability according to the student's goals. Events that promote student's goals are desirable and events that prevent his goals are undesirable. Each event is classified as desirable (marked with a $\mathbf{D}$ in the table), undesirable (marked with a $\mathbf{U}$ ), or with no valenced reaction to the situation (marked with an $\mathbf{N}$ ) in the column "Event's Desirability". As we previously said, we determine the desirability of the events based on what we know about students that have mastery or performance goals. Sometimes, in order to determine if an event is desirable or not, the agent needs to make questions to the student or access other kind of information (for example, the student's effort). These questions are presented in column "Agent's Question". In the column "Student's Response", possible responses given by the student ${ }^{4}$ are presented. The column "Intensity Variables" describes the variables that affect the intensity of each emotion, and, finally, the column "Emotions" presents the elicited emotions of the student. The emotions can be Distress or Joy, Disappointment (marked with Disap) or Satisfaction (marked with Satisf), Gratitude or Anger, and Shame.

When an event is desirable, it elicits the joy emotion, and when it is undesirable it elicits the distress emotion. For example, for a performance oriented student who has the goal of pleasing his parents, to provide a correct response for an exercise is a desirable event because it promotes his goal, and for the same reason, not to provide a correct response is an undesirable event. Events with no valenced reaction do not elicit any emotion.

For the satisfaction and disappointment emotions, it is necessary to know when the event is expected and if it happened or not. The majority of educational events can elicit satisfaction and disappointment emotions because they have a degree of expectedness. When the student is pleased, in sufficient intensity, because a desirable and expected event happened, he feels the satisfaction emotion. When he is displeased because the event did not arise, he has the disappointment emotion. Sometimes, the student can see an undesirable event as an expected desirable event that did not happen. This is the case of the event "the student did not provide a correct response for an exercise". If the event "to provide a correct response for the exercise" is a very desirable and expected event, the student can interpret the event "the student did not provide a correct response for an exercise" as a desirable event that did not happen and so elicit disappointment emotion. The emotions of the student that are elicited for each event are shown in the column "Student's Emotions".

\footnotetext{
${ }^{4}$ Standard expressions available through menus.
} 
The satisfaction and disappointment, as well as joy and distress emotions have opposite valence. The student can not experiment disappointment and satisfaction at the same time. This way, when the student has a disappointment emotion, the satisfaction emotion dies. Since the Mediating Agent aims at promoting a positive mood in the student, it acts in order to cancel the student's negative emotions. So, we consider that the Mediating Agent's interventions always annul the student's negative emotions. But, as we previously said, the affective tactics of the agent will not be discussed in this article.

\section{Elicited emotions when a student has mastery goal orientation}

The events 1, 2 and 3, showed in Table 3, concern the accomplishment of the tasks by students who have mastery goals.

If the mastery oriented student accomplished the task incorrectly or did not finish it (events 1 and 3), it is necessary to know if it was important to him to learn about the pedagogical subject relative to the task, since the mastery oriented students are motivated to learn those subjects that they think are interesting. If he has the goal of learning that subject, it is an undesirable event; otherwise not. When the event is undesirable, distress is elicited. As the student can also perceive this situation as an expected desirable event that did not happen, the student feels disappointment too. The intensity of these emotions depends on the degree of realization of the event, on the event's unexpectedness, and also on the event's desirability. The realization variable can be determined by the grade obtained by the student in the exercise. The degree of realization is higher, if the response is $70 \%$ incorrect than when the response 50\% incorrect and, so, the student is more disappointed in the former situation. We consider that the degree of realization is stronger for the responses in which the degree of incorrectness is superior to $50 \%$. The degree of unexpectedness can be measured by the actual performance of the student. The event "not provide a correct response for an exercise" is less unexpected when the student is having an excellent performance. We consider that when one or more of these variables have a higher degree, an emotion with a higher intensity arises (marked with a ++ ).

If he accomplished the task correctly (event 2), which is a desirable event, it is important to know if he made a high effort. Students with mastery orientation become more satisfied with good results obtained in tasks which they made more effort. The degree of realization and unexpectedness also interferes. It is necessary to verify the grade obtained (if higher, higher is the intensity of satisfaction/joy emotion) and the unexpectedness (if the student always obtains good grades).

A pedagogical subject is composed of chapters (sections of study). If the student finishes the chapter (event 5), when he made all tasks and followed all the content presented, the event is desirable and elicits satisfaction/joy emotions. If he gave up or did not obtain a good grade (event 4), the event is undesirable. In this case it is also necessary to verify the degree of realization (grade) and the unexpectedness of the event. The degree of desirability can also be measured by the interference of this event in the final grade of the course. 
Table 3: Elicited Emotions when a Student Has Mastery Goal Orientation

Student has Mastery Goal orientation

Student's Goal: learn the content.

\begin{tabular}{|c|c|c|c|c|c|c|}
\hline \multicolumn{2}{|c|}{ Event } & \multirow{3}{*}{$\begin{array}{l}\text { Agent's Question } \\
\text { ask the student if it is } \\
\text { important to him to know } \\
\text { the subject of the task }\end{array}$} & \multirow{2}{*}{$\begin{array}{l}\text { Stud. } \\
\text { Resp. } \\
\text { yes }\end{array}$} & \multirow{2}{*}{$\begin{array}{l}\text { Event's } \\
\text { Desirab. } \\
U\end{array}$} & \multirow{2}{*}{$\begin{array}{l}\text { Intensity } \\
\text { Variables } \\
\text { realization } \\
\text { unexpectedness }\end{array}$} & \multirow{2}{*}{\begin{tabular}{|l|}
$\begin{array}{l}\text { Student's } \\
\text { Emotions }\end{array}$ \\
Distress/Disap \\
\end{tabular}} \\
\hline 1 & $\begin{array}{l}\text { Student } \\
\text { provided an } \\
\text { incorrect task }\end{array}$ & & & & & \\
\hline & answer & & no & $\mathrm{N}$ & & $\mathrm{NE}$ \\
\hline \multirow[t]{3}{*}{2} & Student & effort & high & D & \multirow{3}{*}{$\begin{array}{l}\text { realization } \\
\text { unexpectedness }\end{array}$} & Joy/Satisf++ \\
\hline & correct task & & & & & \\
\hline & answer & & low & $\mathrm{D}$ & & Joy/Satisf \\
\hline \multirow[t]{2}{*}{3} & \multirow[t]{2}{*}{$\begin{array}{l}\text { Student did not } \\
\text { accomplish the } \\
\text { task }\end{array}$} & \multirow[t]{2}{*}{$\begin{array}{l}\text { ask the student if it is } \\
\text { important to him to know } \\
\text { the subject of the task }\end{array}$} & yes & $\mathrm{U}$ & $\begin{array}{l}\text { realization } \\
\text { unexpectedness }\end{array}$ & Distress/Disap \\
\hline & & & no & $\mathrm{N}$ & & NE \\
\hline \multirow[t]{2}{*}{4} & \multirow[t]{2}{*}{$\begin{array}{l}\text { Student gave up } \\
\text { the chapter }\end{array}$} & \multirow[t]{2}{*}{$\begin{array}{l}\text { ask the student if it is } \\
\text { important to him to know } \\
\text { the subject of the task }\end{array}$} & yes & $\mathrm{U}$ & $\begin{array}{l}\text { realization } \\
\text { unexpectedness }\end{array}$ & Distress/Disap \\
\hline & & & no & $\mathrm{N}$ & & $\mathrm{NE}$ \\
\hline 5 & $\begin{array}{l}\text { Student finished } \\
\text { the chapter }\end{array}$ & & & D & $\begin{array}{l}\text { realization } \\
\text { unexpectedness }\end{array}$ & Joy/Satisf \\
\hline
\end{tabular}

\section{Elicited emotions when a student has performance goal orientation}

Table 4 deals with elicited emotions for students who have performance goal orientation.

For a performance goal orientated student, the events "did not accomplish the task correctly or did not finish it" are undesirable (events 1 and 3), since the extrinsically oriented students desire to obtain good grades in order to please teacher and parents and do better than their colleagues, and elicits distress emotion. As it happens for mastery oriented students, this situation can be seen as a desirable and expected event (obtain a good grade) that did not happen. These events are even more undesirable if the student made greater effort and so elicits these emotions with higher intensity. If he accomplished the task correctly, it is important to know if he made effort (event 2). Students with performance orientation become more satisfied by good results obtained in tasks in which they made less effort because it implies high ability (Meece \& Mccolskey, 2001). But, if he made efforts, he expects more strongly to have success and, then, the event elicit a high intensity emotion.

If the student finished the chapter with success (event 5), the event is desirable and the student experiences joy/satisfaction emotion.

If the student finished the chapter without success or gave up (event 4), the event is undesirable and elicits distress/disappointment emotions.

The intensity of the emotion above depends on the reality variable. The higher the grade, the higher the level of realization and consequently (the higher) the intensity of the positive emotion. 
Differently, if the emotion is a negative one, the intensity is higher when the student obtains a worse grade. The effort variable also affects the emotion intensity. High effort implies that the emotion's intensity is higher.

The unexpectedness variable also interferes on the emotion's intensity. The degree of unexpectedness can be measured by the actual performance of the student. The event "student provided an incorrect response for an exercise" is less unexpected when the student is having an excellent performance.

Table 4: Elicited emotions when a student has performance goal orientation

Student has Performance Goal Orientation

Student's Goal: have success in tasks and exercises and obtain rewards

\begin{tabular}{|c|c|c|c|c|c|c|}
\hline \multicolumn{2}{|c|}{ Event } & \multirow[t]{2}{*}{ Agent's question } & \multirow{2}{*}{$\begin{array}{l}\text { Stud. } \\
\text { Resp. }\end{array}$} & \multirow{2}{*}{\begin{tabular}{|l} 
Event \\
Desir.
\end{tabular}} & \multirow{2}{*}{$\begin{array}{l}\text { Intensity } \\
\text { Variables } \\
\text { realization/ effort } \\
\text { unexpectedness } \\
\text { undesirability }\end{array}$} & \multirow{2}{*}{\begin{tabular}{|l|}
$\begin{array}{l}\text { Student's } \\
\text { Emotions }\end{array}$ \\
Distress/Disap \\
\end{tabular}} \\
\hline 1 & $\begin{array}{l}\text { Student provided } \\
\text { an incorrect task } \\
\text { answer }\end{array}$ & & & & & \\
\hline 2 & $\begin{array}{l}\text { Student provided a } \\
\text { correct task answer }\end{array}$ & & & $\mathrm{D}$ & $\begin{array}{l}\text { realization/ effort } \\
\text { unexpectedness } \\
\text { desirability }\end{array}$ & Joy/Satisf \\
\hline 3 & $\begin{array}{l}\text { Student did not } \\
\text { accomplish the task }\end{array}$ & & & $\mathrm{U}$ & $\begin{array}{l}\text { realization/ effort } \\
\text { unexpectedness } \\
\text { undesirability }\end{array}$ & Distress/Disap \\
\hline \multirow[t]{2}{*}{4} & \multirow{2}{*}{$\begin{array}{l}\text { Student gave up } \\
\text { the chapter }\end{array}$} & & yes & $\mathrm{N}$ & & $\mathrm{NE}$ \\
\hline & & & no & $\mathrm{U}$ & $\begin{array}{l}\text { realization/ effort } \\
\text { unexpectedness } \\
\text { undesirability }\end{array}$ & Distress/Disap \\
\hline 5 & $\begin{array}{l}\text { Student finished } \\
\text { the chapter }\end{array}$ & & yes & $\mathrm{D}$ & $\begin{array}{l}\text { realization/ effort } \\
\text { unexpectedness } \\
\text { undesirability }\end{array}$ & Joy/Satisf \\
\hline
\end{tabular}

This information presented in Table 3 and Table 4 will be part of the beliefs of the BDI agent. In the next section, we describe the BDI model and its use for the inference of student's emotions.

\section{The BDI Model}

The mental states approach describes an agent as an intentional system, i.e., having certain mental attitudes that are attributed to human beings, like "believe", "need", "desire", etc. But it was necessary to define which mental states are more appropriate. Bratman (1990) proposed the BDI (Belief, Desire, Intention) model which is based on belief, desire and intention mental states. 
The beliefs represent the information about the state of the environment that is updated appropriately after each sensing action. The beliefs can be viewed as the informative component of the system state.

The desires are the motivational state of the system. They have information about the objectives to be accomplished, i. e. what priorities or payoffs are associated with the various current objectives. The fact that the agent has a desire does not mean that the agent will do it. The agent carries out a deliberative process in which it confronts its desires and beliefs and chooses a set of desires that can be satisfied.

The intention is a desire that was chosen to be executed by a plan, because it can be carried out according to the agent's beliefs (because it is not rational that the agent carries out something that it does not believe). Plans are pre-compiled procedures that depend on a set of conditions for being applicable. The desires can be contradictory to each other, but the intentions can not. The intentions represent the currently chosen course of action. The intentions are persistent. An agent will not give up on its intentions - they will persist, until the agent believes it has successfully achieved them, it believes it can not achieve them or because the purpose of the intention is no longer present.

A rational agent will perform actions that it intends to execute without any further reasoning, until it is forced to revise its own intentions due to changes in its beliefs or desires. This may happen because of new events or the failure or successful conclusion of existing ones.

In our tutorial system, the agent's strategies and behaviour are described as the agent's beliefs. The decision of what to do and when to do it are the desires and intentions of the agent. This way, a determined strategy (belief) of the agent is activated if a desire of the agent becomes an intention.

In the next section, we present the BDI model and development tool used in this work: X-BDI.

\subsection{X-BDI: The Logical Model Utilised}

X-BDI (eXecutable BDI) is a BDI agent's model proposed by Móra (1998). The model can be also used as a tool for specification of BDI agents like the current formal models, as an environment for implementation and execution of agents. This way, it is not only an agent specification, but it may also be executed in order to verify the agent behaviour.

In order to reduce the distance between BDI agent's models and their implementation, instead of defining a new BDI logic or choosing an existing one and extending it with an operational model, Móra defines the notions of belief, desires and intentions using a logic formalism that is both welldefined and computational: extended logic programming with explicit negation (ELP) with the wellfounded semantics extended for explicit negation (WFSX). ELP with WFSX extends normal logical programs with a second negation named explicit ${ }^{5}$ negation. According to Móra (1998), this extension allows to explicitly represent negative information (for example, a belief that a property $P$ does not hold) and increases the expressive power of the language.

In the next section, we present the X-BDI tool. The goal is to describe how to specify and implement an agent, from a user's point of view, using X-BDI. More details about the X-BDI and the formalisms used to define the X-BDI model can be found in (Móra, 1998).

\footnotetext{
${ }^{5}$ This is different of negation as failure or negation by default of normal logic programs (Móra, 1998).
} 


\subsection{The Syntax of the X-BDI Tool}

The architecture of the Mediating Agent is divided in two modules: the body and mind. The mind module of the Mediating Agent is responsible for the affective diagnosis and the selection of the affective tactics. The body module is responsible for selecting, in the database of behaviors, an emotive attitude (physical behavior) and speech for the tactic to be applied, since the Mediating Agent is a lifelike pedagogical agent represented by a character ${ }^{6}$ and its tactics are also composed by emotive speeches and attitudes of the character.

$\mathrm{X}$-BDI is a tool for the implementation of an agent's cognitive module ${ }^{7}$. In the case of this work it is used for the implementation of the mind module of the Mediating Agent. Other modules of an agent (such as sensors, effectors and interface) should be implemented using other programming languages and the X-BDI communicates with these other modules through sockets ${ }^{8}$. The body module of Mediating Agent is implemented in Java.

The beliefs (including actions) and desires must be specified in a file called bdi.a, which is loaded when the X-BDI begins its execution. The designer does not need to specify the agent's intentions, since the agent chooses its intentions through its desires. In the beginning of this file, the designer identifies the agent using the predicate identity(Agent_Name).

An action must be represented by the predicate act:

act (ag, action) causes effect if condition

where the attribute $a g$ (agent's identification is optional). An action is composed of preconditions and pos-conditions. Pos-conditions represent the effects and consequences of an action and are represented by effect. The condition is a condition necessary to define a state or execute an action. The pre and pos-conditions can be expressed through the mental states of beliefs and desires.

Beliefs are represented by the predicate bel as follows:

$$
\text { bel (ag, p, t). }
$$

It means that the agent $a g$ believes in a property $p$ at a time $t$. The attribute $a g$ e $t$ are optional. If the attribute $a g$ is not provided, it assumes that it is related to the described agent. If the attribute $t$ is omitted, it assumes the current time.

Desires are described by the predicate des:

$$
\text { des (ag, p, t, prio). }
$$

It means that the agent $a g$ desires the property $p$ with the priority prio in the time $t$. Like in bel, the attributes $a g$ and $t$ area optional. The attribute prio is optional, but if specified it should have a value between zero and one.

Finally, the information received from the environment is described as follows:

[sense $(p, t)$, sense $(p, t), \ldots]$

Each predicate represents a determined property $p$ perceived at a time $t$.

\footnotetext{
${ }^{6}$ The lifelike character of the Mediating Agent is called Pat (Pedagogical and Affective Tutor). See (Jaques \& Viccari, 2004) and (Jaques et al., 2004) for more details about the architecture of this agent.

${ }^{7} \mathrm{We}$ also use the term cognitive kernel in order to refer to a module of an agent implemented in BDI.

${ }^{8}$ A socket is one endpoint of a two-way communication link between two programs running on the network. A socket is bound to a port number in order to identify the application that data is destined to be sent (Sun, 2003).
} 


\section{Affective Recognition and Diagnosis through Mental States}

Let us see how the X-BDI cognitive kernel (the mind of our agent - the Mediating Agent) selects the affective tactics for the following scenario: the student has performance goal and he feels distress and disappointment because he provided an incorrect response to an exercise. The cognitive kernel receives the following information from the agent's sensors:

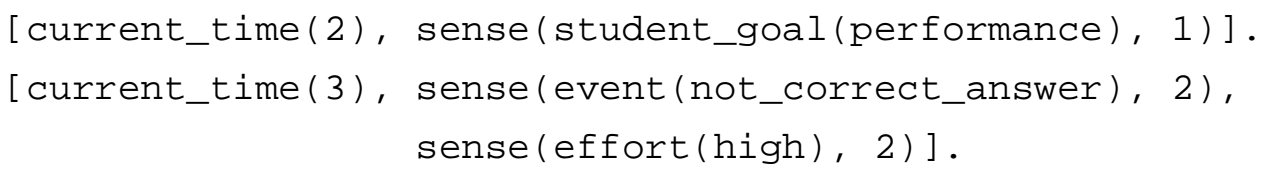

The sensor notifies the BDI cognitive kernel that the student has performance goals and his effort was high, and that an event happened - the student provided an incorrect response to the exercise.

So, the agent activates the desires "apply_tactics" and "emotion_sent" as intentions. The desire "emotion_sent" aims at sending to the Diagnostic Agent the student's emotions. It uses this information for helping the Mediating Agent to choose the pedagogical tactics that are adequate in the cognitive and affective point of view. The desire "apply_tactics" is responsible for choosing the affective tactics that will be applied. The Mediating Agent was identified as "ag".

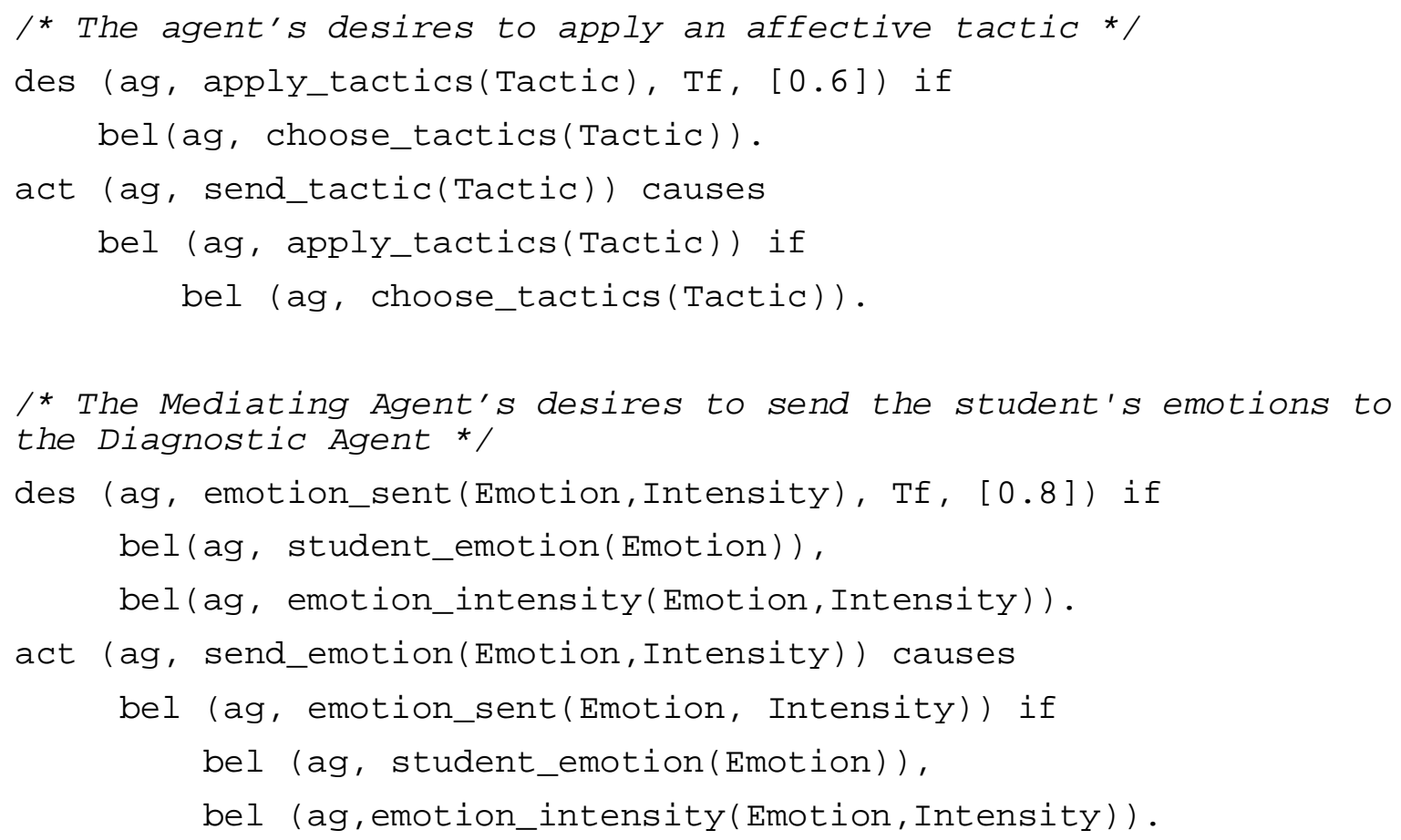

In order for the agent to satisfy its intention of applying an affective tactic, it must accomplish the action of sending this tactic to the agent's actuator ("send_tactic" predicate) - the module of the Mediating Agent responsible for applying an affective tactic. To satisfy the intention "emotion_sent" it needs to send the emotion to the Diagnostic Agent ("send_emotion" predicate).

In order to send the emotions to the Diagnostic Agent, the Mediating Agent must know the student's emotions. It infers the student's emotions from the following beliefs:

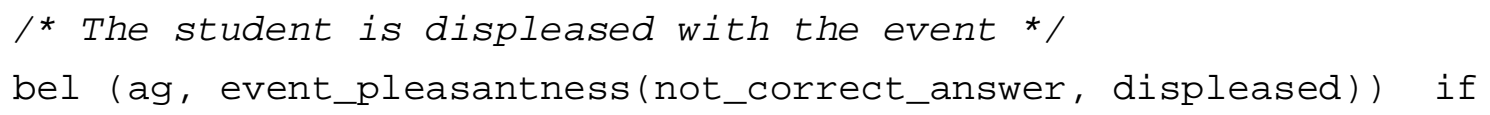




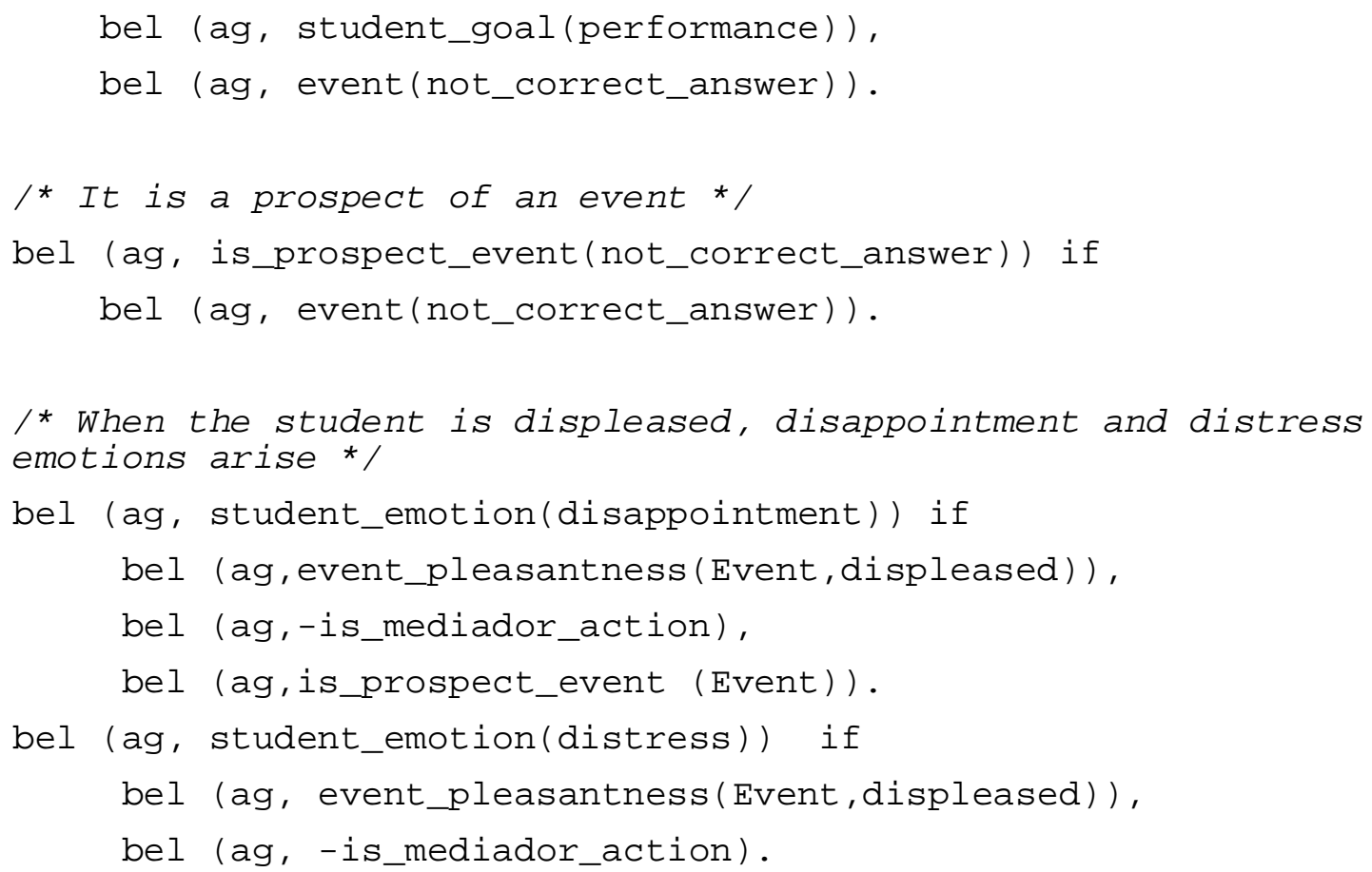

The student is displeased with the event, because the event is undesirable, or it is desirable but it did not happen. When the student is displeased, it experiences distress emotion, and disappointment if it is the prospect of an event that was confirmed ( "is_prospect_event" predicate). It is the case of the event "not_correct_task_answer", since when the student accomplishes a task he has an expectation that this event would happen. It is indicated by the predicate "bel (ag,is_mediador_action)". To elicit disappointment and distress emotions the event should not be caused by the Mediating Agent. The agent's actions elicit emotions as anger and gratitude.

It is also important to verify the value of the variables that affect the emotion's intensity:

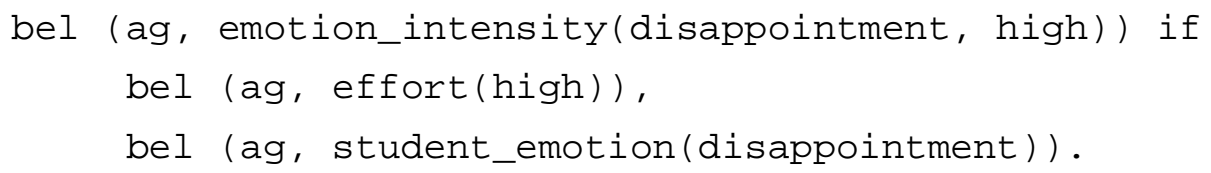

The variables that affect the emotion's intensity are effort, realization, unexpectedness and undesirability for disappointment, and undesirability for distress. If one of these variables has a higher value (marked with high) the student experiences the specific emotion with high intensity, otherwise he experiences emotions with medium intensity. The values of the variables that affect the emotion's intensity are sent by the sensor of the body module and these values can be medium or high. The sensor is responsible for identifying the value of these variables with questionnaires and student's observable behaviour.

Finally, the agent chooses the tactics through the beliefs showed below. The affective tactics are: (1) to increase the student's self-ability, (2) to increase the student's effort; and (3) to offer help to the student. Once it chose the affective tactic, it can accomplish the action of sending the tactic to the actuator module. As this action is the restriction for the elected intention to be satisfied, the agent's intention of applying an affective tactic is accomplished.

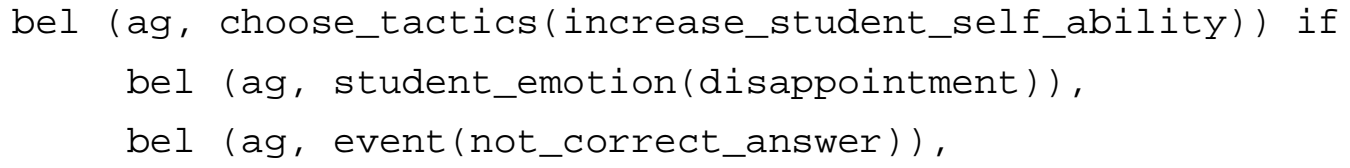




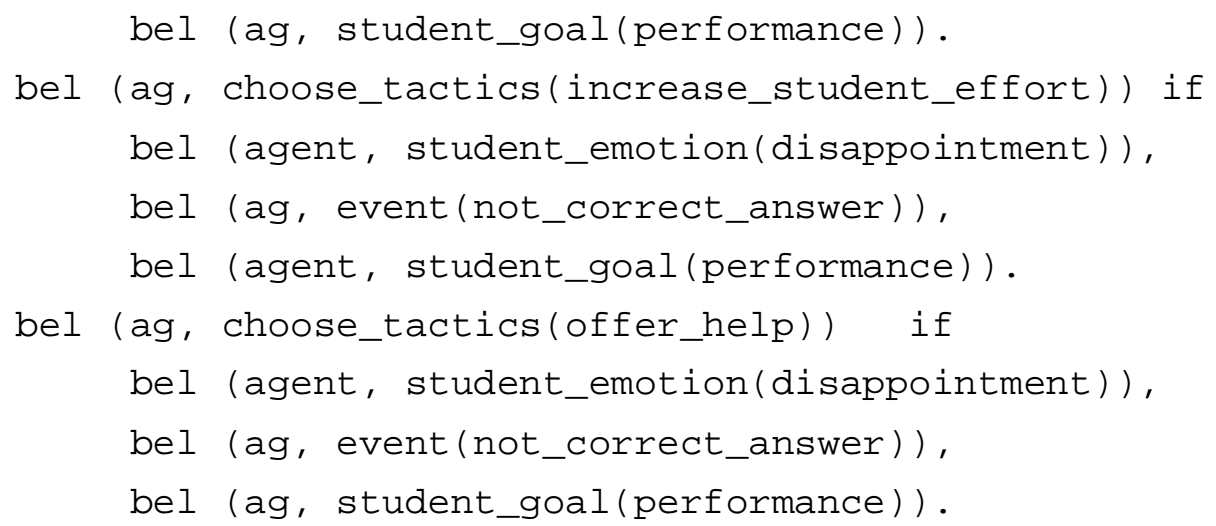

The inference of the student's emotions and the choice of the affective tactics by the X-BDI kernel can be visualized in the interface of the Prolog that is shown in Figure 8. In this case, in order to show in this paper how the X-BDI kernel works, we programmed it to show the result in the Prolog Interface, instead of sending this information to the body of the agent (the way that the agent should behave) via sockets. The set of intentions chosen by the agent's mind for the example previously described are represented by the predicates int_that inside the shaded squares in Fig. 1.In the dark gray square we can see the emotions that were chosen by the intention emotion_sent. The light gray square shows the tactics that were chosen by the intention apply_tactics. The predicates int_to indicate the actions that are made by the agent "ag" (Mediating) in order to satisfy the intentions. 


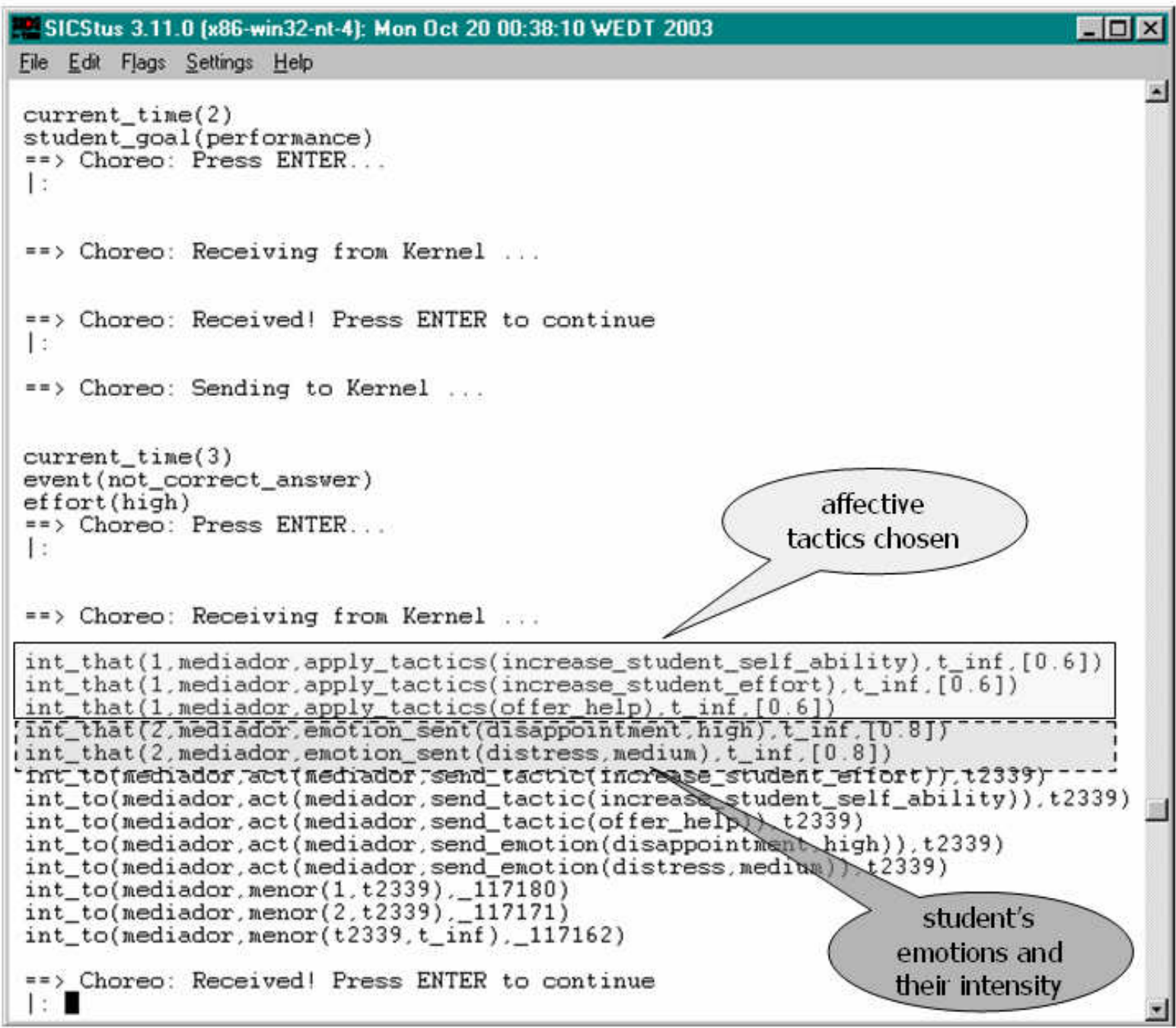

Figure 8 . The choice of the affective tactics by the X-BDI cognitive kernel

When the mind module choose an affective tactic, it sends a message via sockets that contains the type of behavior to be presented to the body module. For example, the mind module desires to present a behavior of "offer help". It must inform the action's type (verbal or physic) and the behavior's type (salutation, encouragement, increase student's self-ability, help, etc). First, the body module randomly chooses a behavior of the required type (generally, the mind module sends a physical and verbal behavior together). After the agent has chosen a behavior, it generates an HTML page with the JavaScript code for the agent's movements and presents it in the student's browser. The agent's character is implemented in Microsoft Agent (2002). The browser reads the HTML page and sends the JavaScript code to the Microsoft Agent (installed in the user's machine) that will present the behavior defined in the code.

\section{Conclusions}

In this paper we described the use of the BDI approach for the implementation of the mind of an affective pedagogical agent that infers student's emotions, models these emotions and chooses an appropriate affective tactic according to these emotions. The choice of the mental states approach for this implementation is based on the cognitive approach of emotion (Scherer, 1999), which considers 
that emotions are elicited by a cognitive evaluation of the personal significance of an agent, object or action (appraisal). This way, the agent deduces the affective state of the student through a BDI reasoning which aims at discovering the cognitive evaluation (his appraisal) made by the student. To do so, it needs to know the events that are happening, the student's goals and the desirability of the events according to student's goals.

Besides, the affective model must be dynamic enough to consider the changes in the emotional states (Bercht \& Viccari, 2000). Since the motivation and the affectivity of the student may vary in a very dynamic way (the student may not feel satisfied at some determined moment and feel more satisfied in another one), the use of the BDI approach for the implementation of the student model show to be very convenient, because it allows simple revisions and frequent modifications of the information about the student (Bercht \& Viccari, 2000). The student model is built dynamically from each interaction in real-time.

The BDI approach has been used by our research group at UFRGS as tool for modelling the cognitive abilities of the student (Giraffa \&Viccari's (1999) work) and also his motivation and the affective state displeased (Bercht \& Viccari's work, 2000). Our work differs from Bercht and Viccari's work (2000) in the methodology used to recognise the student's emotions. In their work, the inference of the student's appraisal was made by an expert that inserted the related rules as beliefs of the agent. In this case, events are mapped directly to emotions. In our work the inference of student's appraisal is made by the agent itself. An advantage of our proposal is that it is not necessary for an expert to determine all the rules for the student's affective state inference in order to implement them in the agent in advance. The agent deduces the student's emotions by reasoning about his appraisal from the information that it has about the student.

We see that a future work can be to extend the belief-desire-model, more specifically the XBDI (the BDI tool used in the implementation of this thesis), in order to also include personality traits, emotions, and moods. According to de Rosis (2002), this approach offers several advantages. The first one is that it opens the opportunity of driving consistent behaviours of agents from a model of their cognitive state: the system of beliefs, desires, and intentions may trigger emotions, regulate the decision of whether to show or to hide them, and finally, drive externalized actions. In this case, we are incorporating an architecture of emotions (emotion synthesis) in the agent in order for it to generate affective behaviour more consistent and believable.

\section{References}

Ames, C. (1990) Motivation: What Teachers Need to Know. Teachers College. 91, 3, 409-21.

Andrade, A. et al (2001). A Computational Model of Distance Learning Based on Vygotsky's Sociocultural Approach. Proceedings of AI-ED 2001 Workshop Papers: multi-agent architectures for distributed learning environments.

Bercht, M; Viccari, R. (2000) Pedagogical agents with affective and cognitive dimensions. Proceedings of the Congreso Iberoamericnao de Informatica Educativa, Vina del Mar.

Bratman, M. E. (1990) What is intention? In: Cohen, P., Morgan, J., and Pollack, M. (Eds.) Intentions in Communication. MIT Press, Cambridge, MA, 15-31.

Damasio, A. (1994) Descartes' Error. New York: G. P. Putnam.

Ekman, P. (1999) Facial Expressions. In Dalgleish, T. \& Power, T. (Ed.). The Handbook of Cognition and Emotion. Sussex, U.K.: John Wiley \& Sons, 301-320.

Frijda, N. (1994) Varieties of affect: emotions and episodes, moods, and sentiments. In Ekman, P. \& Davidson, R. J. (Ed.). The Nature of Emotion. New York: Oxford Univ. Press, 59-67.

Georgeff, M. et al. (1999) The Belief-Desire-Intention Model of Agency. Proceedings of the International Workshop on Intelligent Agents V, Agent Theories, Architectures, and Languages, 5., Paris: Springer-Verlag, 1-10.

Giraffa, L.; Viccari, R. M. (1999) Towards a New Perspective for ITS: Using a Mentalistic Approach to Model Cognitive Pedagogical Agents. International Journal of Continuing Engineering Education and Life Long Learning. Osaka, v.9. 
Goleman, D. (1995) Emotional Intelligence. New York: Bantam Books.

Izard, C.E. (1984) Emotion-cognition relationships and human development. In Izard, C.E.; Kagan, J. \& Zajonc, R.B. (Eds.). Emotions, cognition, and behavior. New York: Cambridge University Press. pp. 17-37.

Jaques, P. A.; Viccari, R. (2004) A BDI Approach to Infer Student's Emotions. Proceedings of Ibero-American Conference on Artificial Intelligence, 2004 nov. 22-26, Puebla, México, 901-911.

Jaques, P. A. et al. (2004) Applying Affective Tactics for a Better Learning. Proceedings of the European Conference on Artificial Intelligence (ECAI) 2004, aug. 22-27, Valencia, Spain, 109-113.

Järvela, S. (1998) Socioemotional aspects of student’s learning in a cognitive-apprenticeship environment. Instructional Science 26: 439-472. Netherlands: Kluwer.

Kopecek, I. (2000) Emotions and Prosody in Dialogues: An Algebraic Approach Based on User Modelling. Proceedings of the ISCA Workshop on Speech and Emotions. Belfast: ISCA, 184-189.

Lepper, M.; Chabay, R. (1988) Socializing the intelligent tutor: bringing empathy to computer tutors. In: Mandl, H; Lesgold, A. M. (Ed.). Learning Issues for Intelligent Tutoring Systems. New York: Springer-Verlag, 242-257.

Meece, J. \& McColskey, W. (2001) Improving Student Motivation. Serve. Available at: http://www.serve.org/Products/ ProdPub.php.

Microsoft Agent. (2002) http://www.microsoft.com.

Móra, M. C. et al. (1998) BDI models and systems: reducing the gap . Proceedings of the International Workshop on Intelligent Agents V, Agent Theories, Architectures, and Languages. Paris.

Ortony, A. et al. (1988) The cognitive structure of emotions. Cambridge Univ. Press, UK.

Piaget, J. (1989) Les relations entre l'intelligence et l'affectivité dans le developpement de l'enfant. Rimé, B.; Scherer, K. (Eds.) Les Émotions. Textes de base en psychologie. Paris: Delachaux et Niestlé, 75-95.

Picard, R. (1997) Affective Computing. Cambridge: MIT Press. 262 ps.

Picard, P. et al. (2001) Toward Machine Emotional Intelligence: Analysis of Affective Physiological State. IEEE Transactions Pattern Analysis and Machine Intelligence, 23(10).

Pintrich, P. et al. (1991) A Manual for the Use of the Motivated Strategies for Learning Questionnaire. TR 91-B-004. The Regents of the University of Michigan.

Reeves, B. \& Nass, C. (1996) The Media Equation: How people treat computers, television, and new media like real people and places. New York: Cambridge University Press.

de Rosis, F. (2002) Toward Merging Cognition and Affect in HCI. Applied Artificial Intelligence, Philadelphia, v. 16, n. 7-8, 487-494.

Scherer, K. R. (1999) Appraisal Theory. In Dalgleish, T.; Power, M. (Eds.) HandBook of Cognition and Emotion. John Wiley \& Sons Ltda.

Scherer, K. (2000) Psychological models of emotion. In J. Borod (Ed.) The neuropsychology of emotion. Oxford/New York: Oxford University Press, 137-162.

del Soldato, T.; de Boulay, B. (1995) Implementation of Motivational Tactics in Tutoring Systems. Jounal of Artificial Intelligence in Education, v. 6, nro. 4,. 337-378.

Sun. (2003) Custom Networking: all about sockets. http://java.sun.com/docs/books/tutorial/networking/sockets/.

Tcherkassof, A. (1999) Les indices de préparation à l'action et la reconnaissance des expressions émotionnelles faciales. Revue Européenne de Psychologie Appliquée. 49(2), 99-105.

de Vicente, A. \& Pain, H. (2002) Informing the detection of the students' motivational state: an empirical study. Proceedings of International Conference on Intelligent Tutoring Systems, 6., 2002, Biarritz, France. Berlin: Springer-Verlag, 933-943.

Vygotsky, L. S. (1994) The Problem of the Environment. The Vygotsky Reader. Cambridge, MA: Blackwell, 338-354.

Wehrle, T.; Kaiser, S. (2000) Emotion and Facial Expression. In A. Paiva (Ed.). Affective Interactions - Towards a New Generation of Computer Interfaces. Berlin: Springer, 49-63. 